Check for updates

London, UK

jane@janefeinmann.com

Cite this as: BMJ 2021;372:n263

http://dx.doi.org/10.1136/bmj.n263

Published: 03 February 2021

COVID-19

\title{
Why aren't covid-19 vaccines being manufactured in standard prefilled syringes?
}

\section{Prefilled syringes are the safest and standard recommended delivery device for most modern vaccines-so why are covid-19 vaccines being packaged in glass vials in the middle of a global glass shortage? Jane Feinmann reports}

\section{Jane Feinmann freelance journalist}

By 24 January 2021 more than 5.8 million people in the UK had been given their first dose of covid-19 vaccine. The achievement is all the more remarkable given the tough and time consuming safety precautions that must be taken. For the AstraZeneca injection, healthcare professionals, working alone or in pairs, take "full responsibility" for following a lengthy, itemised standard operating procedure, which was published for NHS use only by the Specialist Pharmacy Service on 7 January 2021.

As well as guidance on preparing the workstation and removing vaccines from the refrigerator, the checklist involves a 12 step guide to filling up to 10 syringes from each vaccine vial. This involves carefully cleansing the vial "bung" before puncturing it in 10 different places to withdraw each dose into a single use syringe. This procedure is far removed from normal vaccination practice. At least in high income countries, prefilled syringes are now the norm for influenza injections, heparin injections, and millions of injectable medications. This is in line with the Royal Pharmaceutical Society's guidance on the safe and secure handling of medicines ${ }^{1}$ to "minimise the manipulation of medicines outside of pharmacy," said William Harrop-Griffiths, chair of the Royal College of Anaesthetists' Clinical Quality and Research board, at its launch in 2018.

David Whitaker, a retired anaesthetist and chair of the patient safety committee of the European Board of Anaesthesiology, is concerned that the decision to use multidose vials for covid-19 vaccinations ignores this guidance. "The method is unchanged from Jonas Salk's polio vaccinations over 70 years ago," says Whitaker. "It's as if people are being made to use fountain pens and bottles of ink instead of biros."

\section{Emergency}

The anomaly is partly explained by the emergency need-the unpredictability around vaccine approval over the past few months followed by the "near instantaneous clamour across the world to stock up on vaccines and the ancillary products required for their delivery," according to Simone Blayer, who oversees vaccine process development at PATH, a non-profit global health organisation. ${ }^{2}$

"Across the world, we were looking at up to four billion doses to be deployed in the first quarter after a vaccine is approved for manufacture," he said in August 2020. "Many plants today can fill and finish tens of thousands of vaccine doses per hour, but when the immediate need is for billions of doses, even the fastest robotic filling arm can be too slow. For this reason, the first wave of vaccines was always going to have multiple doses in each vial."

In July 2020, the medical technology company BD confirmed that the UK government's order for 65 million syringes at the time would be "unlikely to be delivered in prefilled syringes due to the accelerated speed with which the vaccination programme needs to be rolled out." 3 The same month, Pfizer confirmed that it was considering multidose vials instead of single use "to allow for more efficient production as they can be filled faster." 4

Reports of a global shortage of medical glass, said to be a key factor in slowing down "fill finish" or bottling of the product, have raised concerns. ${ }^{5}$ These, however, seem to be unfounded. "We've been hearing these rumours, but it's not causing a problem, at least in the UK," Zoltan Kis, research associate at the Future Vaccine Manufacturing Hub at Imperial College London, told The BMJ. A spokesperson for AstraZeneca also confirmed that, as of 18 January, "there is certainly no glass vial shortage in the UK."

\section{Patches}

The NHS might now be in a position to look at logistics for the future, as covid-19 vaccination looks set to become routine, much like flu vaccination. On 12 January, Kate Bingham, former head of the government's vaccine taskforce, told the Public Accounts Committee that deployment of the vaccine needs to be simplified if, as expected, it turns out that people will need further doses in the future. She told MPs that this would be "ideally oral or intranasal or even a patch where you could just get it sent in the

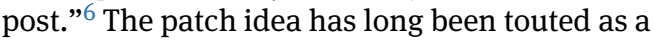
promising alternative to the flu vaccine without a practical application emerging. ${ }^{7}$

Yet Bingham failed to mention prefilled syringes, widely tried and tested, easy to use, and almost entirely safe, lacking human factor risks. "Given the importance to life and the national economy, it's surprising that with nearly a year to prepare, a superior and available technology like [prefilled syringes] does not appear to have been considered and is still not under consideration in the UK," says Whitaker. 
In November 2020 the US International Development Finance Corporation approved a $\$ 590 \mathrm{~m}$ (£430m; €485m) loan ${ }^{8}$ to Apiject, a North Carolina company, to support the building of US based facilities to produce up three billion single dose prefilled plastic injectors per year "capable of delivering almost all leading covid-19 vaccine candidates with speed, scale and efficiency"-with the US as a priority purchaser. It's not clear whether prefilled syringes will be produced at the UK government's cutting edge Vaccines Manufacturing Innovation Centre-currently being built in Oxfordshire and set to "make 70 million doses within a four to five month period, enough for everyone in the country," says, Matthew Duchars, chief executive of the centre. ${ }^{9}$

The success so far of Britain's vaccination programme could be seen as an argument in favour of sticking with multiple dose vials. "It's clear from the huge numbers being vaccinated at the moment that healthcare professionals are managing well with multidose vials, which are also the cheapest way to deliver them,' says Kis. "Cost will always be a factor in vaccination programmes, especially globally." Multidose vials remain widely used for most drugs in low and middle income countries because they are seen as offering the lowest cost per injection. But Apiject says this is a myth and that "the supply chain for making, filling, and finishing glass vials and syringes has become inflexible, slow, expensive, and outdated." 10 Its single dose prefilled injector is both the cheapest and safest method of delivery, it claims, avoiding wastage as well as the potential for contamination, with 'a single machine turning out 180 million plastic containers, made specifically for COVID-19 vaccines, and aseptically filling them with an exact drug dose, every year.

Whitaker argues that prefilled syringes, as used for annual flu vaccines, are the most up-to-date, safe, and efficient format. "At this stage, in this continuing emergency, it's important that crucial decisions are made on the back of patient safety experience at the coalface by people who understand what it's like to deliver vaccinations at speed and with the need for constant vigilance to ensure that every dose is delivered safely."

Provenance and peer review: Commissioned; not peer reviewed

Competing interests: I have read and understood BMJ policy on declaration of interests and have no relevant interests to declare.

1 Royal Pharmaceutical Society. Professional guidance on the safe and secure handling of medicines 2018. https://www.rpharms.com/recognition/setting-professional-standards/safe-and-securehandling-of-medicines/professional-guidance-on-the-safe-and-secure-handling-of-medicines

2 Subramanian S. Without vials and needles, a virus vaccine is just a formula. Bloomberg 2020 Aug 12. https://www.bloomberg.com/features/2020-covid-vaccine-manufacturing-essentials/

3 Government orders 65m syringes ahead of potential Covid-19 vaccine. Pulse 2020 Jul 14. https://www.pulsetoday.co.uk/news/clinical-areas/immunology-and-vaccines/government-orders65m-syringes-ahead-of-potential-covid-19-vaccine/

4 Furlong A. Europe's challenge of a lifetime: manufacturing enough coronavirus vaccines. Politico. 18 Jul 2020. https://www.politico.com/news/2020/07/18/europes-challenge-of-a-lifetime-manufacturing-enough-coronavirus-vaccines-369064

5 Hart C. Three key challenges for the covid vaccine supply chain. Supply Management. 8 Jan 2021 https://www.cips.org/supply-management/news/2021/january/three-key-challenges-for-thecovid-vaccine-supply-chain/

6 Vaccine could be a "patch in the post" next winter." Daily Telegraph2021 Jan 12. https://www.pressreader.com/uk/the-daily-telegraph/20210112/281715502254707

7 News NIH. in Health. Flu vaccine skin patch tested. Sep 2017. https://newsinhealth.nih.gov/2017/09/flu-vaccine-skin-patch-tested

8 US International Development Finance Corporation. DFC approves $\$ 590$ million loan to Apiject to expand infrastructure and deliver critical vaccines in response to the covid-19 pandemic. Nov 2020. https://www.dfc.gov/media/press-releases/dfc-approves-590-million-loan-apiject-expandinfrastructure-and-deliver

9 Elsom J. The entire population of the UK could be vaccinated against new covid variants within four months when a new f158million state-of-the-art vaccine production hub opens in Oxfordshire later this year, say experts. Daily Mail 2021 Jan 17. https://www.dailymail.co.uk/news/article9155183/Entire-UK-vaccinated-against-new-Covid-variants-four-months-factory.html

10 Apiject. The Apiject story. https://apiject.com/wp-content/uploads/2021/01/Apilect-Story_25.pdf
This article is made freely available for use in accordance with BMJ's website terms and conditions for the duration of the covid-19 pandemic or until otherwise determined by BMJ. You may use, download and print the article for any lawful, non-commercial purpose (including text and data mining) provided that all copyright notices and trade marks are retained. 